\title{
Intersetorialidade: possibilidade de parcerias entre a Estratégia Saúde da Família e a Pastoral da Criança
}

Intersectoriality: possibility of partnerships between the Family Health Strategy and the Pastoral Care of the Child

Fabrine Costa Marques' ${ }^{1}$ Karine Suene Mendes Almeida Ribeiro², Warley Queiroz Santos ${ }^{3}$

' Pós-Graduanda em Gestão de Serviços e Sistemas em Saúde pela Universidade Estadual de Montes Claros (UEMC) - Montes Claros (MG), Brasil.

brine87@hotmail.com

${ }^{2}$ Mestre em Enfermagem pelas Faculdades Unidas do Norte de Minas (FUNORTE) Montes Claros (MG), Brasil.

karine_suene@yahoo.com.br

${ }^{3}$ Graduando em Direito pelas Faculdades Unidas do Norte de Minas (FUNORTE) -

Montes Claros (MG), Brasil.

warleyqueiroz@hotmail.com
RESUMO Trata-se de estudo descritivo/qualitativo, com o objetivo de conhecer a percepção dos enfermeiros com relação à parceria com a pastoral da criança. Para coleta de dados, utilizou-se entrevista semiestruturada e os dados foram analisados através da análise do discurso. A percepção foi considerada relevante ante a viabilidade do acompanhamento intensivo das crianças. As estratégias utilizadas pelas equipes na concretização da parceria foram: reuniões; processos de referência e contrarreferência; educação continuada e pesagem. A parceria mostrou-se relevante e efetiva na promoção da saúde, sobretudo na prevenção e no combate de doenças prevalentes na infância.

PALAVRAS CHAVE: Intersetorialidade; Programa Saúde da Família; Desenvolvimento da comunidade; Promoção da Saúde.

ABSTRACT This is a descriptive-qualitative study aiming to understand the perception of nurses regarding the partnership with pastoral care of children. For data collection, we used semi structured interviews and data were analyzed using discourse analysis. The perception was considered relevant at the feasibility of intensive monitoring of children. The strategies used by the teams in the implementation of the partnership were: meetings; reference and counter-reference processes, continuing education and weighing. The partnership proved to be relevant and effective in promoting health, particularly in preventing and combating common childhood diseases.

KEYWORDS: Intersectioriality; Family Health Program; Community development; Health promotion 


\section{Introdução}

Visando à melhoria da qualidade de vida e de saúde, a Política Nacional de Promoção da Saúde estabelece, como uma de suas diretrizes, o estímulo de açóes intersetoriais que propiciem o desenvolvimento integral das açóes de Promoção da Saúde, ou seja, açóes que possibilitam responder às necessidades sociais em saúde. Na busca dessa melhoria, o Ministério da Saúde aposta e investe na Estratégia Saúde da Família (ESF), novo modelo de atenção básica à saúde (BRASIL, 2006a).

Projeto dinamizador do SUS, a ESF é entendida como uma estratégia de reorientação do modelo assistencial atuante em um território e em uma população delimitada, de modo a intervir sobre os fatores de riscos aos quais ela está exposta. Constituída por uma equipe multiprofissional, objetiva desenvolver atividades de promoçãa, proteção e recuperação da saúde, características do nível primário de atenção. Para prestar assistência integral, estabelece vínculos de corresponsabilidade com a população e açóes intersetoriais por meio de parcerias estabelecidas com diferentes segmentos sociais e institucionais, de forma a intervir em situações que transcendem a especificidade do setor saúde e que têm efeitos determinantes sobre as condições de vida e saúde dos indivíduos-famílias-comunidade (BRASIL, 2004).

A intersetorialidade constitui novas estratégias de planejar, executar e controlar a prestação de serviços a fim de garantir um acesso igual dos desiguais (JUNQUEIRA, 2004). Nesse sentido, ela apresentase como um dos eixos estruturantes das políticas públicas de saúde (PAULA; PALHA; PROTTI, 2004).

Durante os estágios do PISEC (Projeto de Integração Serviço Ensino e Comunidade), disciplina ofertada pela Faculdade e realizada em Unidades Básicas de Saúde, percebi a importância da relação existente entre a ESF, na qual fiz estágio, e a comunidade. Essa relação configura-se como exemplo de uma ação intersetorial, haja vista a promoçâo da saúde por meio da busca do bem-estar de todos que dela participam. Ademais, verifica-se ali a ocorrência de momentos para a prevenção de doenças e a eliminação da desnutrição infantil, um dos princípios gerais do Capítulo I da Política de Atenção Básica, aprovada pela Portaria no 648/ GM de 28 de março de 2006 (BRASIL, 2007).

Nessa ESF, a Pastoral da Criança, juntamente com os funcionários da Unidade, realiza um evento festivo, a 'Celebraçáo da Vida'. Essa, conforme a Pastoral da Criança (2007), é caracterizada pela celebração do desenvolvimento das crianças pesadas nesse dia. Com seu caráter aparentemente lúdico, essa ação intersetorial propicia um maior comparecimento das crianças à ESF. Durante o evento, as crianças são pesadas e as famílias se reúnem para celebrar as crianças que estão bem e, ao mesmo tempo, ajudar as crianças que estáo em dificuldades.

A Pastoral da Criança é uma entidade associativa e representativa da sociedade. Suas açóes, baseadas na solidariedade humana e na partilha do saber, segundo a Pastoral da Criança (2007), visam a agir na promoção da Saúde e no desenvolvimento integral das crianças até os seis anos de idade, bem como em seus contextos familiar e comunitário, a partir de iniciativas de caráter preventivo que fortaleçam o tecido social e, outrossim, a integração entre a família e a comunidade. Em Montes Claros, a Pastoral da Criança está presente em várias regióes da cidade, promovendo, com a sociedade, uma convivência de solidariedade e respeito, valorizando as diferenças entre as pessoas.

Além de realizar, em Montes Claros, mensalmente, o programa de pesagem das crianças, com direito a lanches, programações e comemoraçôes de aniversários, mediante convênio com o Ministério do Desenvolvimento Social e Combate à Fome (MDS) e o Instituto de Desenvolvimento do Norte e Nordeste de Minas Gerais (IDENE), a Pastoral atua no Programa de Aquisição de Alimentos - Programa do Leite (PAA-Leite). Esse, através do cadastro dos beneficiários, consiste na distribuição do leite, na vigilância e no monitoramento nutricional, e, ainda, no controle social (BRASIL, 2006b)

Esta pesquisa objetivou caracterizar os sujeitos; conhecer a percepção do Enfermeiro da ESF com relação à parceria com a Pastoral da Criança; identificar as estratégias adotadas por ele com vistas à sua concretização, bem como os fatores que a dificultam, facilitam e/ 
ou motivam, podendo, dessa forma, instigá-los a uma maior reflexão sobre o tema posto e, consequentemente, à implementação dessa prática em seu território, na busca de um melhor acompanhamento da saúde das crianças, seja na prevenção ou no tratamento de doenças.

\section{Metodologia}

O presente estudo trata-se de uma pesquisa descritiva e qualitativa. Essa é caracterizada, segundo Minayo (2006), por ser um método:

[...] que se aplica ao estudo da história, das relaçóes, das representaçóes, das crenças, das percepçóes e das opinióes, produtos das interpretaçôes que os humanos fazem a respeito de como vivem, constroem seus artefatos e a si mesmos, sentem e pensam. (MINAYO, 2006, p.57).

Foram considerados sujeitos da pesquisa os Enfermeiros responsáveis técnicos pelas oito unidades de Estratégia Saúde da Família pertencentes ao Pólo Delfino Magalhães, no município de Montes Claros/MG, em um total de oito enfermeiros, representados através da amostragem intencional.

Para o levantamento e a construção dos dados foi utilizada a técnica de entrevista semiestruturada, com duração média de trinta minutos. Triviños (1992, p. 146) privilegia a

entrevista semi-estruturada porque esta, ao mesmo tempo que valoriza a presença do investigador, oferece todas as perspectivas possiveis para que o informante alcance a liberdade e a espontaneidade necessárias, enriquecendo a investigação.

Foi realizada uma entrevista Pré-teste no dia 09 de fevereiro de 2010, com uma enfermeira de uma ESF não pertencente à Macro-região Delfino Magalhães, para ajuste e avaliação do roteiro de entrevistas.
Após aprovação da pesquisa pelo Comitê de Ética em Pesquisa da FUNORTE (Faculdades Unidas do Norte de Minas), sob o parecer 0364/09, foram agendadas as entrevistas por telefone. As mesmas foram realizadas em ambiente reservado, no local de trabalho dos entrevistados. Esses concordaram em assinar, em duas vias, o Termo de Consentimento Livre e Esclarecido, atendendo às recomendaçôes da Resoluçấo no 196/96 sobre pesquisa envolvendo seres humanos. Foilhes assegurado o sigilo das informaçóes fornecidas e seu anonimato, já que foram identificados por nomes de guerreiros. Para fins de fidedignidade e transcriçáo na íntegra das falas, foi solicitada a autorização para gravar a entrevista em MP4, entretanto, nem todos autorizaram.

Utilizou-se a técnica de Análise do Discurso, que tem como objetivo

realizar uma reflexão geral sobre as condiçôes de produção e apreensão da significação de textos produzidos nos mais diferentes campos: religioso, filosófico, jurídico e sócio-politico. (MINAYO, 2006, p. 211).

Consoante a autora, na Análise de Discurso, o texto é abordado como unidade complexa de significações, enquanto o discurso é a linguagem em interação. Orlandi (1996) defende a construção da Análise de Discurso não como uma alternativa para a linguística, ciência que explica a linguagem verbal humana, mas como uma proposta crítica, a qual procura justamente problematizar as formas de reflexão estabelecidas.

A análise dos dados qualitativos foi realizada em dois momentos: primeiro, a ordenação dos dados; em seguida, a classificação dos mesmos. Os temas identificados foram agrupados por afinidade e organizados em cinco categorias.

\section{Análise dos discursos}

\section{Caracterizaçáo dos Sujeitos}

Ao se definirem as características dos profissionais entrevistados, verificou-se que $100 \%$ deles eram do sexo 
feminino. Esse dado reflete de forma expressiva a feminização da força de trabalho em Enfermagem, o que, para as autoras Lopes e Leal (2005, p.109), ocorre devido aos aspectos sócio-históricos dessa profissão. Para elas, a enfermagem nasce como um serviço organizado de instituições religiosas "associado à figura da mulher-mãe que desde sempre foi curandeira e detentora de um saber informal de práticas de saúde, transmitido de mulher para mulher", impondo à profissão, por longo período, exercício institucional exclusivo e ou majoritariamente feminino e caritativo.

Com relação à faixa etária, $62,5 \%$ estão com menos de 29 anos de idade e $37,5 \%$ entre os 30 e 34 anos.

É importante destacar a formação complementar dos enfermeiros das Estratégias de Saúde da Família da Macro-região Delfino Magalhães. A maioria dos entrevistados possui Residência Multiprofissional em Saúde da Família ou ainda é residente. Ademais, dois daqueles possuem Mestrado Profissionalizante em Ciências da Saúde. Desse modo, verifica-se que, a despeito de náo ser considerado um requisito, os profissionais daquelas ESFs detêm qualificação acima da exigida para o desempenho de sua função.

Analisando o tempo dos entrevistados no cargo, verificou-se que todos náo se enquadram em um dos critérios de exclusão, que é possuir experiência em Unidade de Saúde da Família inferior a um ano. À exceção de 03 (três), os quais exercem a função há mais de cinco anos, a maioria a exerce há 2 (dois) anos.

Entre os oito entrevistados, metade possui outra ocupação: três trabalham como enfermeiros em um Hospital Universitário e um exerce a docência. Embora a Estratégia Saúde da Família estabeleça, através da Portaria n648/GM, de 28 de março de 2006, "o cumprimento de horário integral - jornada de 40 horas semanais - de todos os profissionais nas equipes de saúde da família" (BRASIL, 2007, p. 23), tal fato não lhes exclui o direito ao acúmulo remunerado de cargo público, quando houver compatibilidade de horários, conforme a Constituição, em seu artigo 37, inciso XVI, alínea $b$ e $c$ (BRASIL, 2010).

\section{Percepção dos enfermeiros com relação à parceria entre a ESF e a Pastoral da Criança}

Os profissionais entrevistados consideraram de grande importância a ação intersetorial entre a Pastoral da Criança e a ESF, sendo essa opiniáo incorporada na maioria dos discursos, como no da seguinte fala:

Na minha opiniäo, penso que é muito importante, porque o trabalho da Pastoral é muito consolidado e tem uma excelente adesão da população para todos os eventos e açóes que eles fazem. [...] só vem a acrescentar o nosso trabalho. (William Wallace).

Em duas falas, percebe-se a importância da parceria relacionada, de maneira restrita, ao acompanhamento das crianças. Já em outra, o entrevistado faz menção à complexidade do trabalho oferecido pela Pastoral, que também inclui o acompanhamento do idoso.

A parceria, ela é importante, uma vez que a gente soma esforços no acompanhamento de crianças. (Hércules).

Acho extremamente importante a parceria para facilitar o acompanhamento às crianças da área. (She-Ha).

Eu acho importante. A gente trabalha com faixa etária parecidas. Eles (a Pastoral) trabaIham com a criança, a gente também trabalha com a criança, eles trabalham com o idoso, a gente também. É de suma importância, é um trabalho complementar ao nosso e que, quando funciona direito, é excelente, sem dúvidas. (Máximus).

Outro entrevistado revela náo ter uma opiniáo bem formada, devido ao fato de sua ESF não ter uma efetiva participação com a Pastoral. Todavia, na fala seguinte, ele ressalta a seriedade da parceria, uma vez que o "desenvolvimento de açóes intersetoriais, integrando projetos sociais e setores afins, voltados para a 
promoção da saúde" (BRASIL, 2007, p. 21), é uma característica intrínseca ao processo de trabalho das equipes de Saúde da Família, estabelecida pela Política Nacional de Atenção Básica.

[...] por ser exatamente um trabalho intersetorial para construir a ESF, seria muito mais interessante se a gente tivesse esse trabalho junto, em parceria. Como qualquer parceria é bem-vinda na saúde, até porque a gente sabe que sozinha a ESF não tem como funcionar muito não. (Power Rangers).

\section{Estratégias adotadas pelo enfermeiro com vistas à concretização da parceria entre a ESF e a Pastoral da Criança}

O reconhecimento de um problema, para Starfield (2004), é uma consideração particularmente importante com relação à atenção primária. Os profissionais da atenção básica, para a autora, devem reconhecer primeiro as necessidades que existem tanto na comunidade como nos pacientes, individualmente, a fim de formular um diagnóstico ou entendimento. Posteriormente, instituir uma estratégia ajustada ao tratamento ou manejo e realizar um arranjo para reavaliaçáo, verificando a adequação do diagnóstico e tratamento.

$\mathrm{Na}$ busca da concretização do processo descrito acima, no discurso a seguir, é possível identificar claramente a intenção do profissional entrevistado de resolver um problema de sua comunidade utilizando a estratégia da reunião para consolidar a parceria com a Pastoral. Entretanto, não obteve sucesso.

Aqui no PSF, nós estamos tendo um problema em relação à pesagem das crianças. Elas não estavam vindo na chamada nutricional. Então a gente marcou uma reunião com uma pessoa da Pastoral da Criança, ela veio. A Pastoral náo procurou a gente para dar uma resposta se iam unir as pesagens... A gente já tentou duas vezes, mas náo foi para frente não. (Tempestade).
Em contrapartida, o processo de parceria é concretizado com sucesso em outras ESFs, conforme falas posteriores.

A principal estratégia é a pesagem. Essa pesagem acontece uma vez por mês, os agentes vêm até a pesagem para ajudar nesse momento que é acompanhado e é anotado o nome das crianças de risco nutricional ou desnutridas, a gente aproveita esse momento para oferecer a vitamina $A$ também, que é uma coisa do PSF que faz junto nessa pesagem. Algumas datas comemorativas, na outra unidade que eu tinha experiência, a gente fazia junto o Dia das Crianças, das Mães, a gente aproveita também para comemorar em parceria com Pastoral. (Hércules).

[...] visita elas (lideres da Pastoral) fazem também e algumas crianças que estão em situação de risco, elas passam para a gente também acompanhar junto com elas. (Hércules).

Observou-se, após a análise dos discursos, que as estratégias utilizadas pelos profissionais entrevistados são variadas. Isso ocorre, segundo Starfield (2004), porque as necessidades das comunidades são diferentes. Com efeito:

Nenhuma meta especifica para o desempenho ou resultados dos serviços de saúde baseados na comunidade está prescrita, uma vez que se reconhece que as comunidades diferem e que as necessidades mudam de lugar para lugar e de época para época. (STARFIELD, 2004, p. 553).

$\mathrm{Na}$ fala abaixo, nota-se a intencionalidade do profissional de aprimorar o trabalho da Pastoral, apesar de seus líderes já houverem sido preparados, de início, conforme Pastoral da Criança (2007), por meio da capacitação, utilizando o Guia do Líder. 
Uma das estratégias é convidar a Pastoral para participar de algumas atividades aqui na Unidade, principalmente relacionadas à criança e à mulher, especialmente à gestante, para poder estimular a própria educação permanente da Pastoral, porque eles têm a capacitação deles. [...] convidar para o processo educativo [...] toda vez que tem um tema novo, que é interessante, que é importante o agente (ACS) saber; entáo a gente convida o pessoal da Pastoral; eles vêm; eles têm uma boa aderência. (Mulher Maravilha).

Outras estratégias utilizadas foram os processos de referência e contrarreferência, como as mencionadas nos discursos a seguir.

[...] eles (lideres da Pastoral) estão sempre em contato para saberem quem foi a criança que pesou, quem foi a criança que não pesou. Eles nos procuram também para saber questôes de alguns dados relacionados às crianças que estão em baixo peso, e vice-versa. Existe comunicação sim. [...] quando a criança está na faixa etária que é prioritária fazer a puericultura, a gente faz, mas quando náo é, eu solicito para continuar pesando na Pastoral e na chamada nutricional aqui. (William Wallace).

[...] meio que indiretamente, a gente está fazendo um trabalho, mas não tem parceria estabelecida, assim de estar encaminhando os casos, de eles estarem recebendo como contrarreferência, a gente não tem isso. Mas sempre quando eu tenho uma criança em dificuldade, eu aconselho a procurar (a Pastoral) por causa dos complementos alimentares, também por causa dos medicamentos; eu gosto muito do xarope oferecido pela Pastoral; [...] o 'Leite pela Vida', ele é passado (pela Pastoral). [...] Então, quando eu tenho criança, eu tenho idoso, eu os encaminho, peço que eles (Pastoral) passam complemento, e eles (Pastoral) não encaminham para cá. Mas quando tem alguma coisa relevante, porque eles (Pastoral) precisam também de estar com o cartão em dia, e a gente também faz esse acompanhamento, ai eles (Pastoral) acabam falando. (Máximus).

\section{Fatores que dificultam a parceria entre a ESF e a Pastoral da Criança}

Um dos fatores dificultadores do processo intersetorial entre a ESF e a Pastoral da Criança, mencionado pelos entrevistados, foi a divisão territorial. O que é constatado na fala seguinte:

A gente não tem como concretizar (a parceria) porque, na verdade, com a segmentaçâo do território, que é longilíneo, fica complicado a gente tentar concretizar a parceria com algumas das Pastorais, porque quem é do [...] (bairro que faz parte da área de abrangência), ai a gente deveria concretizar (a parceria) lá, mas lá é um pedaço só. Então é muito segmentado mesmo, o território é igual a uma colcha de retalho. E ai a gente escolhe uma Pastoral, uma outra microárea fica muito distante para participar, então fica muito ruim. Até pela questão de não ter nenhuma Igreja Católica em nosso território, apesar de estar próximo. [...] pela questão territorial não é muito viável. (Power Rangers).

De fato, a dificuldade em implementar a parceria com a Pastoral da Criança ocorre porque essa " [...] se organiza em vários níveis de coordenação, aproveitando a estrutura da Igreja Católica, formada por dioceses, paróquias e comunidades" (PASTORAL DA CRIANÇA, 2007, p. 299), diferentemente da delimitação evidenciada nas ESFs, a qual é definida por um Segmento Territorial. Esse é conceituado na Portaria no 750, de 10 de outubro de 2006, como sendo:

[...] um conjunto de áreas contiguas que pode corresponder à delimitação de um Distrito Sanitário, de uma Zona de Informação do IBGE 
ou a outro nivel de agregação importante para o planejamento e avaliação em saúde no $\mathrm{Mu}$ nicípio. É a divisáo territorial utilizada para a análise espacial dos dados em um determinado municipio. (BRASIL, 2006c).

Tanto a implementação quanto a manutenção das ações intersetoriais são consideradas um desafio para os atores sociais envolvidos. Magalhães e Bodstein (2009) defendem que as principais dificuldades para a concretização de parcerias ocorrem porque os representantes setoriais trazem às arenas de negociação uma agenda previamente definida. Ou seja, eles não apresentam flexibilidade em suas propostas.

A dificuldade mencionada acima é observada em alguns dos discursos.

O que dificulta, talvez, nessa parceria ai, seria mesmo o tempo, disponibilidade tanto dos profissionais quanto da Pastoral, para estar realizando reunióes frequentes, discutindo alguns assuntos... (He-Man).

A unica parte que eu acho mais dificil de concretizar é com relaçâo à pesagem, porque a pesagem da Pastoral é no final de semana e, como são duas equipes [...], e [...] uma é no sábado e a outra é no domingo, ai fica difícil a gente acompanhar. (Mulher Maravilha).

\section{[...] o dia da pesagem, que é no sábado, então} a gente teria que estar cedendo nosso horário de estar aqui, ou eles também estarem cedendo em ter que vir aqui no meio da semana, então isso é um fator dificultador. (Tempestade).

Preocupando-se com o acesso, a qualidade e a humanização na Atenção à Saúde, os participantes da 11 a Conferência Nacional de Saúde (CNS) deliberaram e propuseram afirmar que a ESF é porta de entrada do Sistema de Saúde, devendo, assim, garantir uma equipe multiprofissional em dedicação integral e uma adequação às necessidades e prioridades locais, sem modelos programáticos verticalizados
(CONFERÊNCIA NACIONAL DE SAÚDE, 2003). Diante de tal deliberação, percebe-se, através dos discursos acima, que várias ESFs não estâo preparadas para atender a uma das propostas estabelecidas na $11^{\mathrm{a}}$ CNS, uma vez que não apresentam flexibilidade nos horários de atendimento.

Então a gente poderia dividir e tentar concretizar, ou nem concretizar, mas criar um laço; mas também não é um anseio da equipe neste momento; dos próprios agentes comunitários de saúde, que são os responsáveis pela chamada nutricional ou pesagem. (Power Rangers).

$\mathrm{Na}$ fala acima, a dificuldade consiste na falta de interesse da equipe de saúde em concretizar a parceria. Outro entrevistado já aponta como fator dificultador o entendimento dos líderes da Pastoral com relação ao seu papel.

A Pastoral tem seu papel, que é diferente. Muitas vezes algumas lideres da Pastoral até se confundem com o papel de agente. [...] eu já tive um problema em relaçẫo a isso que é o de confundir o papel da Pastoral com o do agente. Elas (lideres da Pastoral) até questionam que fazem a mesma coisa e náo são remuneradas. Ai eu tive que explicar que é função de cada um, deixar bem claro qual o papel do funcionário e do voluntário, pois o papel deles (Pastoral) é voluntário... (Hércules).

A explicação do entrevistado é válida, uma vez que devem ser bem esclarecidas as funçóes de cada uma das entidades envolvidas. No Guia do Líder, manual de capacitação dos líderes da Pastoral, é bem claro, na citação a seguir, o caráter espontâneo dado às suas açóes.

A Pastoral da Criança está presente nas comunidades para agir na promoção da saúde e do desenvolvimento integral de gestantes, crianças e suas famílias. E essa ação acontece porque há pessoas que se comprometem a fazer um 
trabalho 'voluntário', no qual compartilham seus conhecimentos, experiências e uma parte de seu tempo. (PASTORAL DA CRIANÇA, 2007, p. 15).

Já o agente comunitário de saúde aponta como elementos motivadores para o trabalho a remuneração, a dedicação de tempo integral, a possibilidade de aprendizado e profissionalização no campo da enfermagem. Embora não disponha de um saber específico ou auferido por instituição reconhecida, por meio de suas açóes intersetoriais e apoio social, é percebido como conhecedor da população, organizador do acesso ao serviço de saúde, vigilante de riscos e controlador da aderência aos cuidados de saúde propostos pelo médico e pelo enfermeiro. Destarte, constitui-se um trabalhador singular em saúde (MENDONÇA, 2004).

Para grande surpresa, em dois discursos foi mencionada como empecilho para ação intersetorial com a Pastoral a dificuldade de relacionamento interpessoal. Fato que é de se estranhar, uma vez que a Pastoral "promove uma convivência de respeito, solidariedade, valorização das diferenças entre as pessoas" (PASTORAL DA CRIANÇA, 2007, p. 12).

A dificuldade que a gente tem é porque, agora, uma das pessoas que está à frente dessa Pastoral teve um desentendimento com a antiga equipe e a gente herdou isso. (Máximus).

No momento, devido a problemas de relacionamento, não há uma parceria. Mas há intenção da ESF em iniciar a parceria. Um dos membros que fazia parte da Pastoral da Criança tinha problema particular com a ESF, o que dificultava a parceria. Segundo informaçôes, esse membro não tem mais ligação com a Pastoral, sendo então uma das nossas prioridades iniciar a parceria. (She-Ha).

A dificuldade em implementar açóes intersetoriais na Atenção Básica também é reconhecida em outros estudos. Giovanella et al. (2009) analisam que a integração e a intersetorialidade são desafios nem sempre convergentes, que persistem na fase de consolidação da ESF.

\section{Fatores que motivam e/ou facilitam o es- tabelecimento da parceria entre a ESF e a Pastoral da Criança}

O líder da Pastoral da Criança faz 'Visita Domiciliar', acompanhando gestantes e, no máximo, 15 crianças de famílias próximas à sua casa. Realiza o 'Dia da Celebração da Vida' e a pesagem, mensalmente, reunindo as famílias para celebrar o desenvolvimento de suas crianças e a 'Reunião para Reflexão e Avaliação', na qual avalia o trabalho realizado no mês (PASTORAL DA CRIANÇA, 2007). Anjos (2007) ainda aponta que o trabalho desses agentes é feito com populações empobrecidas do país, e visa, basicamente, à difusão de saberes e técnicas de cuidado da saúde de mulheres grávidas e crianças e ao acompanhamento das condiçóes de saúde de crianças de zero a seis anos.

$\mathrm{Na}$ análise dos discursos, observou-se a motivaçâo vinculada ao acompanhamento das crianças.

[...] o que motiva é porque é um acompanhamento até mais intensivo, o agente (ACS) passa uma vez e a Pastoral vai e passa mais uma vez. Na pesagem, os dois veem essa criança novamente... (Hércules).

Eu acredito o que possa estar motivando essa parceria seria mesmo o acompanhamento das crianças, $o$ acompanhamento nutricional das crianças. (Tempestade).

A motivação é a questão da própria repercussão da Pastoral, porque o trabalho da Pastoral é muito bem feito, continuo, e assim, tem excelentes resultados. Então, assim, tudo isso motiva a gente quando a gente sabe que tem uma criança acompanhada, uma gestante [...]; eu até me sinto assim, até mais feliz pelo fato de ser mais um recurso para 
comunidade. [...] por a gente acreditar no trabalho deles, que é muito bom. (William Wallace).

O trabalho intensivo da Pastoral atuante na comunidade foi apontado pelos profissionais da ESF como fator motivador e facilitador das açóes intersetoriais.

O que facilita é porque a Pastoral também tem esse trabalho muito aberto, eles recebem todas as crianças que procuram o serviço, então o acesso também não é difícil. (Máximus).

O que facilita é o acesso, de que está na área de abrangência, quem coordenam são pessoas que estão aqui... (He-Man).

Facilita na questão de que os dois orientam a questão principalmente da alimentação, da amamentação... (Hércules).

O que facilita é que o lider da Pastoral da Criança, ele é inato, então ele está fazendo aquilo porque quer, por vontade, não por dinheiro, e sim por uma missão maior, um amor ao indivíduo, um amor à sua comunidade. Então é muito mais fácil você lidar com alguém que está fazendo com amor do que com alguém que está fazendo por dinheiro, por obrigação [...]. (Mulher Maravilha).

Aqui, verifica-se a propositura pelo entrevistado de um momento de reflexâo sobre a parceria.

O Saúde da Família tem os mesmos ideais e funçóes que a Pastoral da Criança. Só que o Saúde da Familia de forma mais ampliada e a Pastoral da Criança com enfoque em reduzir a mortalidade infantil e enfoque agora relacionado com o idoso. Voltado para a criança, mulher e idoso. $O$ agente comunitário e o lider da Pastoral da Criança desempenham as mesmas atividades e funçōes, a diferença é que a Pastoral não é remunerada e o Saúde da Família é remunerado. O Lider da Pastoral, ele deve ser pautado como um parceiro, porque ele está desempenhando o mesmo objetivo do Saúde da Família, então para que você dividir forças e por que náo somar as forças com a Pastoral? (Mulher Maravilha).

\section{Considerações Finais}

Ao final deste estudo, foi possível conhecer a percepção dos enfermeiros no que concerne à parceria. Essa foi considerada por eles de extrema importância no acompanhamento das crianças. As estratégias adotadas para a concretização da relação intersetorial, quando presentes, foram variadas, limitando-se, contudo, à realidade social da respectiva comunidade.

Os fatores facilitadores e motivadores do estabelecimento da parceria em estudo foram avaliados como positivos, uma vez que os entrevistados relacionaram a presença dela com os bons trabalhos desenvolvidos pela Pastoral. As dificuldades encontradas revelaram-se no processo territorial, no relacionamento interpessoal, bem como na compatibilização de horários entre as entidades envolvidas.

Embora haja empecilhos, como em toda parceria, a ação intersetorial entre a Pastoral da Criança e a ESF trata-se de uma relação bastante válida e efetiva na prevenção e promoção da saúde, bem como na proteção contra agravos das doenças prevalentes na infância. Destarte, ante a sua importância, a ação intersetorial ora analisada constitui-se objeto de estudo de inquestionável relevo social, a qual, com vistas ao seu aprimoramento, pode e deve figurar como tema de pesquisas futuras. 


\section{Referências}

ANJOS, G. Maternidade, cuidados do corpo e "civilização" na Pastoral da Criança. Revista Estudos Feministas, Florianópolis, v.15, n.01, p.27-44, jan/abr. 2007.

BRASIL. Constituição (1988). Constituição da República Federativa do Brasil: promulgada em 5 de outubro de 1988. 3. ed. São Paulo: Saraiva, 2010. 1519 p.

Ministério da Saúde. Secretaria de Vigilância em Saúde. Política Nacional de Promoção da Saúde. Brasília: Ministério da Saúde, 2006a. 60 p. Disponível em: < http://bvsms.saude.gov.br/ bvs/publicacoes/PoliticaNacionalPromocaoSaude.pdf>. Acesso em: 22 jun. 2010.

Ministério do Desenvolvimento Social e Combate à Fome. Desenvolvimento Social. Em visita a Montes Claros, Ministro Patrus afirma que Programa do Leite gera trabalho e garante alimentação. Brasília: Ministério do Desenvolvimento Social e Combate à Fome, 20 setembro 2006b. Disponível em: <http://www.mds.gov.br/ noticias/>. Acesso em: 06 out. 2008.

Secretaria de Atenção à Saúde. Portaria n.750, de 10 de outubro de 2006. Diário Oficial da União, Brasília, n. 197, out. 2006c. Disponível em:< http://www.in.gov.br/imprensa/visualiza/index. jsp?.jornal=1\&pagina=79\&data=13/10/2006>. Acesso em: 02 maio 2010.

Ministério da Saúde. Secretaria de Atenção à Saúde. Departamento de Atenção Básica. Política Nacional de Atenção Básica. 4. ed.. Brasília: Ministério da Saúde, 2007. 68 p. Disponível em: <http://portal.saude.gov.br/portal/arquivos/pdf/volume_4_ completo.pdf>. Acesso em: 08 nov. 2009.

Ministério da Saúde. Departamento de Atenção Básica. Saúde da Família. Brasília: Departamento de Atenção Básica, 2004. Disponível em: <http://dab.saude.gov.br/atencaobasica.php>. Acesso em: 14 ago. 2009.

CONFERÊNCIA NACIONAL DE SAÚDE (Brasil). Conferência Nacional de Saúde, 11, 2000, Brasília. O Brasil falando como quer ser tratado: efetivando o SUS: acesso, qualidade e humanização na atenção à saúde com controle social: relatório final. Brasília:
Ministério da Saúde, 2003. 198 p. Disponível em: <http://dtr2001. saude.gov.br/editora/produtos/livros/popup/03_1444.htm>. Acesso em: 03 maio 2010.

JUNQUEIRA, L. A. P. A gestão intersetorial das políticas sociais e o terceiro setor. Saúde e Sociedade, São Paulo, v.13, n.01, p.25-36, jan/abr., 2004.

LOPES, M. J. M.; LEAL, S. M. C. A feminização persistente na qualificação profissional da enfermagem brasileira. Cadernos Pagu, Campinas, n.24, p.105-125, jan./jun., 2005.

MAGALHÃES, R.; BODSTEIN, R. Avaliação de iniciativas e programas intersetoriais em saúde: desafios e aprendizados. Ciência \& Saúde Coletiva, Rio de Janeiro, v. 14, n. 03, p. 861-868, maio/jun. 2009.

MENDONÇA, M. H. M. de. Agente Comunitário de saúde: o ser, o saber, o fazer. Caderno de Saúde Pública, Rio de Janeiro, v. 20, n. 05, set/out, 2004, p. 1433-1434. Disponível em: < http:// www.scielo.br/scielo.php?script=sci_arttext\&pid=S0102311X2004000500041 > Acesso em: 16 abr. 2012.

MINAYO, M. C. S. O Desafio do Conhecimento: pesquisa qualitativa em saúde. 9. ed. São Paulo: Hucitec, 2006. 406 p.

ORLANDI, E. P. A linguagem e seu funcionamento: as formas do discurso. 4. ed. Campinas: Pontes, 1996. 276 p.

PASTORAL DA CRIANÇA. Guia do Líder da Pastoral da Criança. 10. ed. Curitiba, 2007. 304 p.

PAULA, K. A.; PALHA, P. F.; PROTTI, S. T. Intersetorialidade: uma vivência prática ou um desafio a ser conquistado? O discurso do Sujeito Coletivo dos Enfermeiros nos núcleos de saúde da Família do Distrito Oeste - Ribeirão Preto. Interface - Comunicação, Saúde, Educação, Botucatu, v.08, n.15, p. 331-348, mar./ago., 2004.

STARFIELD, B. Atenção Primária: equilíbrio entre necessidades de saúde, serviços e tecnologia. Brasília: UNESCO Brasil, Ministério da Saúde, 2004. 726 p.

TRIVIÑOS, A. N. S. Introdução à Pesquisa em Ciências Sociais: a pesquisa qualitativa em educação. São Paulo: Atlas, 1992. 176 p.

Recebido para publicação em Fevereiro/2012

Versão definitiva em Junho/2012

Suporte financeiro: não houve

Conflito de interesse: inexistente 